\title{
LABORATÓRIO QUÍMICO-PRÁTICO DO RIO DE JANEIRO - PRIMEIRA TENTATIVA DE DIFUSÃO DA QUÍMICA NO BRASIL (1812- 1819)
}

\author{
Nadja Paraense dos Santos \\ Departamento de Química Orgânica, Instituto de Química, Universidade Federal do Rio de Janeiro, 21949-900 Rio de Janeiro - RJ
}

Recebido em 29/1/03; aceito em 6/10/03

\begin{abstract}
"LABORATÓRIO QUÍMICO-PRÁTICO DO RIO DE JANEIRO" - THE FIRST ATTEMPT AT ESTABLISHING THE SCIENCE OF CHEMISTRY IN BRAZIL (1812- 1819). Until the present date, historians of science have described inaccurately the first laboratory created in Brazil for establishing and divulging Chemistry, namely the "Laboratório Químico-Prático do Rio de Janeiro". During recent research carried out in the Arquivo do Museu Imperial (Petrópolis, RJ), I localized a document entitled "Ensaio histórico analítico das operações do Laboratório Químico-Prático do Rio de Janeiro", which allowed me to gain the relevant information to correct some of the observations made in the first chronicles.
\end{abstract}

Keywords: history of the sciences; Laboratório Químico-Prático do Rio de Janeiro; history of Chemistry in Brazil.

\section{INTRODUÇÃO}

Este artigo pretende divulgar a descoberta de um documento que se encontrava desaparecido até a presente data. Trata-se do documento intitulado "Ensaio histórico analítico das operações do Laboratório Químico-Prático do Rio de Janeiro", onde seu autor discorre sobre as atividades do Laboratório Químico-Prático do Rio de Janeiro, no período de 1812 a 1819.

A descoberta do texto integral esclarece alguns pontos até então obscuros sobre suas verdadeiras funções, as reais operações realizadas, os motivos de sua extinção e sobre o responsável pelo laboratório ao longo de quase sete anos de existência. O presente trabalho não pretende esgotar a análise das operações realizadas no Laboratório Químico-Prático do Rio de Janeiro, mas sim, num primeiro momento, divulgar a descoberta de um documento sobre os primórdios da implantação da atividade química no país e tentar mostrar a inserção do mesmo na cultura científica do período, onde a ciência só se justificaria por suas aplicações práticas, no caso, visando o aumento da riqueza do Estado português.

Tendo como base os dados encontrados na época de suas pesquisas, Rheinboldt ${ }^{1}$, Mathias ${ }^{2}$, Schwartzman $^{3}$, Gonçalves ${ }^{4}$, Carrara Jr. e Meirelles $^{5}$ e Ferraz ${ }^{6}$, em geral, consideram o plano de criação do Laboratório Químico-Prático ambicioso e destacam sua curta duração. O laboratório é tido como a primeira tentativa de incrementar pesquisas químicas com objetivos práticos de aplicação, não tendo a finalidade de desenvolver a química como ciência. Rheinboldt ${ }^{1}$ considera que as primeiras operações químico-industriais do Brasil foram executadas nesse laboratório. Em todos os relatos, a única experiência citada detalhadamente foi a que originou a idéia da criação do referido laboratório: a tentativa de tornar rentável o fabrico de sabão sólido, manufaturado na ilha de São Tomé. Aqueles autores também destacam que, em pouco tempo, os trabalhos do laboratório tornaram-se sem valor científico "limitando-se a ligeiros exames de produtos e drogas farmacêuticas" "1,3.

Segundo Gonçalves ${ }^{4}$, o Laboratório Químico-Prático aparece citado no verbete "LABORATÓRIO" do "Diccionario Juridico, Theoretico e Practico" de autoria de Joaquim José Caetano Pereira e Souza, publicado em 1827, em Lisboa:

*e-mail: nadja@iq.ufrj.br

\begin{abstract}
"Laboratorio - A casa em que estão fornos e apparelhos para os trabalhos chimicos. Foi creado hum laboratorio chimicopratico na Côrte do Rio de Janeiro por Decreto de 25 de Janeiro de 1812 "
\end{abstract}

Esta citação é intrigante, uma vez que desde 12 de dezembro de 1801 já existia em Lisboa um Laboratório Químico que, em 1804, foi transferido à Universidade de Coimbra.

As notícias que se tinham até agora sobre o Laboratório Químico-Prático eram incompletas, provenientes de um artigo de autoria de Francisco Maria de Mello Oliveira ${ }^{7}$ (1847-1907), farmacêutico e depois doutor (1883) em medicina pela Faculdade de Medicina do Rio de Janeiro. Mello Oliveira foi o primeiro a ter acesso ao documento original "Ensaio histórico analítico das operações do Laboratório Químico-Prático do Rio de Janeiro" e, com a permissão do Imperador, publicou em 1884 na Revista Pharmaceutica, um dos diferentes periódicos que serviram como órgão de divulgação do Instituto Pharmaceutico do Rio de Janeiro (1858-1888?), os capítulos I e II do referido documento, que tratam das razões da criação deste laboratório e do plano para seu estabelecimento.

O artigo publicado não era mera cópia. Mello Oliveira fez anotações próprias e juntou um apêndice com um estudo comparativo dos trabalhos de química prática nele efetuados em 1813 com os estudos executados nos laboratórios de química da Escola de Medicina e da Escola Politécnica do Rio de Janeiro em 1883 e 1884. Infelizmente até a presente data não foi localizado o artigo completo de Mello Oliveira, já que o mesmo foi publicado em diferentes números da Revista Pharmaceutica e não há indícios da existência da coleção completa8 . Mello Oliveira, que foi Chefe da Farmácia Central do Exército e preparador da cadeira de química analítica da Escola Politécnica, colaborou com Domingos José Freire (1842-1899) em seu livro "Recueil des travaux chimiques" (1880) e publicou vários estudos químicos e farmacológicos sobre plantas brasileiras e seus alcalóides.

Somente na década de 40 do século XX, voltaremos a ter notícia do Laboratório Químico-Prático, através de Oswaldo de A. Costa9 redator da Revista da Sociedade Brasileira de Química, que no volume XVII (1948) reproduziu os decretos de criação e da nomeação do responsável, e um fragmento do artigo de Mello Oliveira, sem as anotações, o que nos leva a crer que já naquela época não era possível ter acesso a uma coleção completa da Revista Pharmaceutica ${ }^{10}$. 
Localizamos na Revista de Farmácia e Odontologia, um artigo de Salles Cunha" intitulado "Um documento para a história do Laboratório Químico-Prático" mas, pela leitura, pudemos verificar que o documento, datado de 30 de agosto de 1820, trata da compra pelo Real Erário do laboratório do Conde da Barca.

Os demais pesquisadores já citados basearam suas descrições e discussões na parte conhecida do documento e alguns ${ }^{1,4}$ destacam que seria importante para a História da Química no Brasil a localização do manuscrito completo, pois com o documento incompleto era impossível fazer um juízo crítico da atuação do Laboratório, do seu diretor e entender as razões que levaram o Rei a encerrar suas atividades.

\section{O LABORATÓRIO QUÍMICO-PRÁTICO}

\section{Aspectos históricos}

Com a vinda de D. João para o Brasil, foram de imediato emitidas pelo novo governo uma série de Alvarás, Decretos, Leis, Decisões, Resoluções e Cartas Régias. Muitas delas, direta ou indiretamente, foram responsáveis pelo início da estruturação das atividades relacionadas com a ciência no país e, apesar de representarem interesses do governo ou de determinados grupos sociais e terem caráter imediatista, foram salutares para o desenvolvimento da ciência.

Para Oliveira ${ }^{12}$, embora estas leis tivessem sido promulgadas no sentido de atender às necessidades prementes da administração, um número significativo não foi além das intenções, revelando o interesse do governo ou da classe hegemônica da época. Outras tiveram consequiências mais duradouras.

Silva ${ }^{13}$ aponta duas características na cultura científica desse período. A primeira é o pragmatismo, isto é, que a ciência só se justificava socialmente se, em vez de ser puramente especulativa e teórica, tivesse imediatas aplicações práticas, seja para o aumento da riqueza do Estado, seja para a melhoria das condições de vida. A segunda é a estatização, já que o Estado tomava a iniciativa das pesquisas a serem efetuadas nos vários ramos da ciência.

A transformação repentina da colônia em sede da Corte significou a transferência de material e de pessoal ligado à ciência. Sem entrar no mérito das medidas tomadas por D. João VI, com a chegada da Corte, em 1808, inicia-se propriamente uma história institucional local, com a fundação de instituições de cunho científico, algumas das quais podemos relacionar com o desenvolvimento da Química no Brasil, entre outras a Escola Médico-Cirúrgica do Rio de Janeiro (1808), o Real Horto Botânico (1808), a Impressão Régia (1810), a Academia Real Militar (1810), o Museu Real (1818, depois Museu Nacional) e o Laboratório Químico-Prático do Rio de Janeiro (1812).

As aulas de Química vinculadas aos cursos da Academia Real Militar e as Escolas de Medicina da Bahia e do Rio de Janeiro, impingiam a esta ciência um caráter de ciência básica, necessária a outros conhecimentos. Ao problema causado pela falta de tradição no estudo da Química verificado também na metrópole e à escassez de recursos, pode-se adicionar a distância dos centros de estudo das ciências, num período em que a química estava se desenvolvendo muito rapidamente ${ }^{6}$.

O Laboratório Químico-Prático foi o primeiro laboratório criado no qual a química não está vinculada ao ensino, tendo como premissa básica, como veremos adiante, a análise de materiais oriundos das diversas colônias portuguesas e que pudessem ser utilizados no comércio, principalmente entre os portugueses e os chineses.

D. João VI formou gabinetes reduzidos com três ministros para seis pastas e, segundo Lima ${ }^{14}$, é possível caracterizar cada fase de seu governo pelas diferentes influências individuais que preponderaram na corte do Rio de Janeiro entre 1808 e 1821 . Os quatro pri- meiros anos pertencem ao Conde de Linhares (Rodrigo de Souza Coutinho, 1755-1812) e sua febril atividade reformadora. Os dois anos seguintes são de relaxamento: nesse período o Conde das Galveas (João de Almeida de Melo e Castro, 1756-1814) acumulou três ministérios, entre eles o de Estado e Negócios da Marinha e Domínios Ultramarinos, até sua morte em 1814, quando foi substituído pelo Conde da Barca (Antônio de Araújo de Azevedo, 17541817), um diletante intelectual e político de horizontes largos. Os dois últimos teriam papéis importantes na história do Laboratório Químico-Prático do Rio de Janeiro.

O Laboratório Químico-Prático, durante os seus sete anos de funcionamento (1812-1819), esteve sob a supervisão do Ministério e Secretaria de Estado e Negócios da Marinha e Domínios Ultramarinos, sendo seus titulares designados como inspetores das atividades: Conde das Galveas, Marquês de Aguiar (interinamente), Conde da Barca e Conde dos Arcos (Marcos de Noronha e Brito, 1769-1828).

\section{A criação e o encerramento das atividades do Laboratório Químico-Prático}

Pelo decreto de 25 de janeiro de $1812^{15}$, o príncipe regente D. João criou, por proposta do $5^{\circ}$ Conde das Galveas, o Laboratório Químico-Prático do Rio de Janeiro.

\begin{abstract}
"Tendo em consideração as muitas vantagens que devem resultar, em benefício de meus fiéis vassalos, do conhecimento das diversas substâncias que às artes, ao comércio e indústrias nacionais podem subministrar os diferentes produtos dos três reinos da natureza, extraídos dos meus domínios ultramarinos, os quais não podem exata e adequadamente ser conhecidos e empregados, sem se aplicarem e fazerem necessárias as tentativas concernentes às úteis aplicações de que são suscetíveis; movido pelo constante impulso da minha real disposição a promover a pública prosperidade: sou servido criar nesta corte do Rio de Janeiro um laboratório Químico-Prático, onde se façam as mencionadas operações, ou outras quaisquer que se julgarem necessárias para o descobrimento de objetos que possam contribuir imediatamente para tão interessantes fins, o qual laboratório, será sujeito à inspeção do meu ministro e secretário de Estado dos Negócios da Marinha e Domínios Ultramarinos, e por ele será organizado na forma das Instruções que para isso tenho dado: ficando encarregado o mesmo ministro e secretário de Estado de fazer dirigir os trabalhos e operações deste estabelecimento, e de me fazer presentes todos os resultados daqueles processos, com as observações analíticas e descrições que forem necessárias para se poder, na prática deles, tirar todas as vantagens e interesses nacionais que propomos nesta criação (...)."
\end{abstract}

Podemos observar pela leitura do decreto de criação que nesse Laboratório a Química não era apenas apreciada em forma de curso teórico, como na Academia Militar (1810) ou no curso avulso da Bahia (1817), mas visava obter aplicações úteis da análise dos produtos e substâncias encontradas na natureza, nos vários domínios portugueses na Ásia e África e no Brasil.

$\mathrm{Se}$, em geral, procura-se ver nas leis promulgadas pelo governo aqui instalado apenas o sentido de atender às necessidades prementes da administração do país, no caso do decreto de criação do Laboratório Químico-Prático podemos perceber reflexos mais gerais, de médio e longo prazos na sociedade, pois visava a possibilidade de diminuir a dependência da Nação da indústria estrangeira.

Para diretor desse laboratório foi nomeado o cônego bacharel Francisco Vieira Goulart (1765-1839), professor régio de filosofia racio- 
nal e moral na cidade de São Paulo (1809-1811). Consta que em 1796, Goulart, que era membro da Academia das Ciências de Lisboa, solicitou autorização para acompanhar ao Brasil o bispo de São Paulo recém-designado, com a proposta de fazer observações mineralógicas e redigir uma descrição físico-econômica do Bispado de São Paulo. Para este fim, solicitou à Real Fazenda uma contribuição anual para ajuda de custos e auxílio das autoridades da Capitania. Os produtos encontrados deveriam ser remetidos ao Real Museu,

\footnotetext{
"os quais deverão já vir analisados, e acompanhados com uma bem circunstanciada relação dos lugares, onde existem as suas matrizes, e do mais que for necessário para se julgar se é ou não conveniente para sua exportação"16.
}

Como não encontramos outros registros referentes a essa atividade, acreditamos que ela não tenha sido levada adiante, mas Goulart veio para o Brasil, instalando-se inicialmente em São Paulo. Encontramos apenas algumas outras informações esparsas sobre ele: foi cônego da Capela Imperial, um dos primeiros diretores da Imprensa Nacional, redator da Gazeta do Rio de Janeiro e bibliotecário da Biblioteca Imperial e Pública da Corte, atual Biblioteca Nacional. No campo científico não há registro de publicações na área da química.

Não encontramos nenhum registro sobre as atividades exercidas por Francisco Goulart no período que vai do término das atividades do laboratório até sua nomeação para funcionário da Biblioteca Imperial. Segundo Azevedo ${ }^{17}$, ele foi nomeado ajudante de bibliotecário da Biblioteca Imperial em 12 de agosto de 1833, depois nomeado bibliotecário efetivo em 1837, cargo que exerceu até sua morte.

Gonçalves ${ }^{4}$ chama a atenção para dois fatos: não existem referências anteriores de quaisquer vinculações de Vieira Goulart com a Química ou com as ciências de modo geral e, após a desativação do Laboratório, não ocupou nenhum cargo relacionado com as ciências.

Mas, Vieira Goulart não abandona de todo seus estudos científicos ao ser nomeado funcionário da Biblioteca Imperial, e envolve-se em uma polêmica ao publicar a "Memória sobre os defeitos que se encontram no sistema metrológico que se organizou no Brasil pela comissão nomeada por decreto de 8 de janeiro de 1833". Nesta memória publicada em $1836^{18}$, e endereçada à Câmara dos Deputados, Goulart destacava as incorreções científicas do texto da comissão, tanto no que se refere ao padrão da "vara" ${ }^{19}$ como também nas medidas de capacidade, solicita novas medições dos padrões e a formação de "stereometras", ou especialistas nas medições de capacidade de sólidos. Pelos dados que pudemos levantar, Goulart participou ativamente da discussão sobre a primeira legislação metrológica do Brasil independente, tendo sido sua memória publicada pelo Senado e colocada à disposição dos membros da Câmara para estudo.

A participação de Francisco Vieira Goulart no debate científico e político sobre o sistema de pesos e medidas a ser adotado no Brasil contraria a afirmação de Gonçalves ${ }^{4}$. Ele também levanta a possibilidade da falta de habilitação técnica de Goulart ter sido responsável pela suspensão das atividades do Laboratório. Esta crítica parece ter sido uma constante durante todo o período de funcionamento do Laboratório e o próprio Vieira Goulart iria defender-se no documento.

O Decreto de 26 de fevereiro de $1812^{15}$ determina o salário do diretor do laboratório Químico-Prático do Rio de Janeiro em $480 \$ 000$ anuais:

"Havendo por Decreto de 25 de janeiro do corrente ano, nomeado o Bacharel Francisco Vieira Goulart, Diretor do Laboratório Químico-Prático que fui servido mandar criar nesta Corte, sujeito à inspeção de meu Ministro e Secretário do Estado dos Negócios da Marinha e Domínios Ultramarinos: hei por bem ordenar que ao referido Diretor se pague por aquele exercício o mesmo honorário de $480 \$ 000$ anuais que percebia como Professor Régio de Filosofia na Cidade de São Paulo (...)

Outro decreto referente a esse laboratório data de 27 de junho do mesmo ano e cria o lugar de fiel do laboratório fixando seu ordenado em $280 \$ 000$.

O laboratório foi instalado em frente à Capela do Espírito Santo (demolida em 1899) no bairro de Mata-Porcos (atual Largo do Estácio). Segundo Gerson ${ }^{20}$, o bairro tinha esse nome, no início do século XVIII, por ser um verdadeiro matagal, onde se refugiavam os porcos das vizinhanças, das criações dos matadouros próximos. Com a chegada da Corte, lá se instalaram fidalgos, como o Conde das Galveas, cujo sítio seria utilizado após sua morte pela rainha Carlota Joaquina ${ }^{21}$.

O modelo de organização adotado seria o do laboratório químico da Universidade de Coimbra e o laboratório deveria ter como anexo um "dispensatório farmacêutico" em que

\footnotetext{
"Deviam vender-se ao público os produtos químicos do laboratório empregáveis nas artes e oficinas, e além disso prepararem-se os medicamentos tanto para fornecimento do mesmo dispensatório, como das boticas da real armada e dos presídios ultramarinos."
}

Ferraz $^{6}$ relata, a partir de documentos encontrados no Arquivo Histórico da Casa da Moeda de Lisboa, que a criação deste Laboratório não agradou ao diretor do Laboratório da Casa da Moeda de Lisboa, Gregório José Seixas. Ao receber uma longa lista de materiais solicitados por Goulart entre os quais "instrumentos e vidros vazios" 22 , respondeu que teria dificuldade de cumprir a ordem recebida, pois também carecia de material, mas enviava algum material "aproveitando a ocasião para reivindicar outros instrumentos para seu estabelecimento" ${ }^{23}$.

Os materiais enviados além de corresponderem a apenas uma pequena parcela do solicitado, ainda chegaram danificados: das 91 peças enviadas (aí incluídas as de ferro), 42 chegaram ao Rio de Janeiro quebradas, pois foram enviadas num mesmo "caixão", peças pesadas e vidraria sem a embalagem adequada ${ }^{24}$.

O Conde das Galveas, folclórico na Corte pelos seus hábitos desregrados, substituiu o dinâmico e reformador D. Rodrigo de Souza Coutinho, Conde de Linhares, após sua morte em 1812, e deu continuidade aos trabalhos de elaboração social e cultural do Brasil iniciados por aquele, embora com menor intensidade e entusiasmo. Sua gestão foi o período de maior atividade do Laboratório Químico-Prático, com a realização de várias análises, incluindo um caso de "pirataria", ao investigar os processos de fermentação realizados no laboratório particular de Antônio de Araújo de Azevedo, futuro Conde da Barca. Este viria substituir Galveas em 1814 e acreditamos que por ter um laboratório próprio com atividades que concorriam com as ao do primeiro, permitiu que durante sua gestão se iniciasse o período de decadência do Laboratório Químico-Prático, situação que seria agravada na gestão do Conde dos Arcos, levando à sua extinção.

O Laboratório foi extinto pelo decreto de 22 de dezembro de $1819^{15}$ em que o governo reconhecia:

\footnotetext{
"não ter podido, até então, por muitos e diversos inconvenientes, organizar e sistematizar como convinha o Laboratório Químico-Prático".
}

Este mesmo decreto determina que os utensílios que ficaram aos cuidados do diretor sejam guardados em depósitos. Os decretos dão 
a entender que o laboratório químico possuía materiais e instrumentos para executar experiências químicas, embora nada se saiba da qualidade nem da quantidade dos bens existentes em seu patrimônio. Oliveira $^{12}$ observa um sentido caótico nas medidas de D. João, ao mencionar que antes mesmo de suspender o funcionamento do Laboratório Químico-Prático, haja determinado a criação de outro laboratório em 27 de outubro de 1819, com quase as mesmas características do anterior, sem ao menos fazer menção aos instrumentos já disponíveis. Não foi observado por Oliveira ${ }^{12}$, porém, que este decreto estatizou um estabelecimento já existente, o laboratório do Conde da Barca.

\section{O DOCUMENTO}

Ao realizarmos no Arquivo do Museu Imperial (Petrópolis, RJ) o levantamento de uma série de documentos relativos à ligação do Imperador D. Pedro II (1825-1891) com as ciências, localizamos no Arquivo Grão-Pará, sob a guarda dos descendentes da família imperial, um documento intitulado "Ensaio Historico Analytico das Operações do Laboratorio Chimico-Pratico do Rio de Janeiro". Trata-se de um manuscrito de 196 páginas, sem identificação de autoria e sem data, mas seu conteúdo sugere que ele foi escrito pelo Diretor do laboratório, o cônego Francisco Vieira Goulart, provavelmente em 1820.

$\mathrm{O}$ autor do documento refere-se a seu criador, o Conde das Galveas, apresentando-o como homem de visão, incentivador das atividades desenvolvidas pelo Laboratório, visando o desenvolvimento de indústrias e a diminuição dos custos de importações. Podese depreender pela leitura do texto que todas as experiências relatadas foram iniciadas em sua gestão e algumas tiveram continuidade até o ano de 1819, quando as atividades do laboratório foram interrompidas. O Laboratório Químico-Prático deixou de ser prioridade do governo quando o Marquês de Aguiar e o Conde dos Arcos estiveram à frente do Ministério Ultramarino. Mas a crítica mais contundente é feita ao Conde da Barca. O documento enfatiza o descaso com o Laboratório, visto que

"no laboratório de Sua Excelência se faziam preparações químicas para o Hospital Militar, e tinha compreendido que esta era a razão porque senão queria promover o adiantamento do Laboratório de Sua Majestade (...)"

O autor demonstra, em vários trechos do documento, uma certa rivalidade com o Laboratório do Conde da Barca, seja através da comparação das análises feitas, seja pela crítica a alguns dos trabalhos de José Caetano de Barros, o farmacêutico responsável pelas operações químicas realizadas no Laboratório do Conde, ou mesmo pela ironia com que trata a solicitação de transferência do Laboratório Químico-Prático, feita por Barca, para local na cidade com "abundância de água". Para Goulart:

"Está visto que em um laboratório a maior quantidade de água, ou quase toda que se gasta é em banhos refrigerantes e em lavar vasos, e que para isto qualquer água serve (...)"

O Conde da Barca solicitou que o diretor procurasse um local na cidade, que tivesse água em abundância, para transferir o referido Laboratório. Goulart vê nesta ordem apenas o intuito de dificultar a continuidade das operações, visto o Conde possuir laboratório que executava trabalhos semelhantes e ainda fazia preparações químicas para o Hospital Militar. Apesar das dificuldades, Goulart consegue um local possível para a mudança, num prédio pertencente à Capela Real da Armada e quando apresenta a solução a Barca, este diz que o Rei desaprovava aquela proposição e que devia procurar outro local.
O autor utiliza o documento como instrumento de defesa e nele relaciona os motivos da decadência do Laboratório, as operações realizadas e a relação que elas tinham com as necessidades "das Artes nascentes que se queriam, e deviam plantar no Brasil". Também enfatiza que possuía as habilitações necessárias para dirigir e estabelecer o plano necessário para o Laboratório Químico-Prático, e se auto-intitula um "Químico Nacional". É interessante o fato de que ele recomenda a criação de um estabelecimento onde se ensine Química aplicada às Artes vinculado à Junta do Comércio.

O documento divide-se em nove partes:

Introdução;

1. Dos motivos que suscitou (sic) a idéia da criação do laboratório;

- 2. Do plano indicado pelo inspetor para, segundo ele, se redigir o sistema orgânico, que devia, sendo aprovado por Sua Majestade, servir de Regulamento ao Laboratório Químico-Prático;

- 3. Das operações que o inspetor ordenou que se fizessem com intuito de obter produtos para o comércio da China, que de algum modo tornasse mais favorável a sua balança;

- 4. Das mais operações que por ordem do Conde de Galveas se fizeram no Laboratório e foram objetos os seus trabalhos mesmo depois do falecimento de Sua Excelência;

- 5. Análise das águas das Laranjeiras;

- 6. Das experiências que se fizeram sobre os vinhos e aguardentes e do que deu motivo a estes trabalhos;

- Fermentação "vinhosa",

- Fermentação "acetosa",

"Agoa ardente"

- 7. Do que se fez no Laboratório enquanto esteve sujeito às ordens do marquês de Aguiar;

- $\quad$ 8. Do que se fez no Laboratório durante a inspeção do Conde da Barca e do Conde dos Arcos.

\section{AS OPERAÇÕES DO LABORATÓRIO QUÍMICO- PRÁTICO}

Vamos nos reportar aos seis últimos capítulos, já que os três primeiros já foram exaustivamente discutidos na literatura por serem os únicos divulgados desde o século XIX. Mesmo assim, cabe-nos acrescentar algumas informações referentes ao Capítulo 2. No plano apresentado por Goulart, autor presumido do documento, para o Laboratório Químico-Prático ele também relaciona gastos com materiais e com o pessoal necessário para o início das operações. Após dois meses, foi nomeado o mordomo do Conde das Galveas para o cargo de Fiel do Laboratório, com ordenado de $280 \$ 000$ anuais, e o direito de ocupar, para sua residência, a parte do imóvel que seria utilizada como o "dispensatório farmacêutico". Apesar dos protestos de Goulart, somente um ano depois (1813) o Conde ordenou que fosse contratado um ajudante com salário de $10 \$ 000$ mensais e uma ajuda de custo de mesmo valor. A prestação de contas dessas despesas devia ser feita de três em três meses, até o final do mesmo ano, quando o diretor deixou de receber tais valores.

Nos Capítulos 3 a 6 encontramos o relato das atividades do Laboratório Químico-Prático, que nos permite entender a razão de sua denominação, bem como a motivação econômica de sua criação e vinculação ao Ministério de Estado dos Negócios da Marinha e Domínios Ultramarinos. Em geral, as operações a serem executadas, propostas pelo Conde das Galveas, tiveram continuidade após sua morte, tendo algumas das quais sido realizadas até 1819. No Capítulo 7 Goulart aproveita o fato de o Marquês de Aguiar ser também o responsável pelo Real Erário, para apresentar uma memória econômica em que trata de impostos e das possíveis falsificações das mo- 
edas de ouro cunhadas no Brasil. No Capítulo 8 ele relata a degradação do Laboratório e seu fim.

O primeiro trabalho oficial do Laboratório Químico-Prático foi a tentativa de descobrir produtos que pudessem ser utilizados para permuta de gêneros com os chineses. $\mathrm{O}$ primeiro produto analisado foi o pau-brasil (Caesalpinea echinata) para utilização em tinturarias. O objetivo seria a extração da fécula corante que seria preparada aqui por conta do Estado. Mas o êxito deste projeto dependia da qualidade do material e do preço. Foi feito o extrato e o projeto não foi adiante, porque os chineses importavam do Sião (atual Tailândia) um lenho mais barato.

A cultura da papoula (Papaver somniferum), conhecida popularmente como papoula do oriente, foi o segundo trabalho. $\mathrm{O}$ objetivo era ensinar a preparar o ópio ${ }^{25}$ a partir do extrato. Foram testadas várias sementes originárias de Bengala e da Ilha de Porto Santo e feitos alguns extratos, mas Goulart diz que estas experiências foram interrompidas com a morte de Galveas, em janeiro de 1814.

$\mathrm{O}$ terceiro produto a ser estudado foi a aguardente de cana, que deveria ser purificada para eliminar o "mau cheiro" e levada ao mesmo teor alcóolico do rum que os ingleses exportavam das Antilhas. Aqui também, o custo da operação inviabilizou o projeto, pois o baixo preço da aguardente de arroz não permitia a introdução e venda, na China, de outros "licores espirituosos" por preço vantajoso.

As operações que se seguiram também tinham por objetivo a procura nas colônias portuguesas de produtos que fossem economicamente viáveis para o comércio e, por conseqüência, incentivassem a indústria e a agricultura. Segundo Goulart:

"O Conde das Galveas, imbuído em mais sólidos princípios de economia política (...) dizia, que ficaríamos reduzidos ao último estado de pobreza, se limitando-nos ao cultivo das matérias primas (...)"

Foram realizados exames em cerca de cem (100) "lenhos e cascas tintoriais" provenientes de Minas Gerais, Ceará, Santa Catarina, São Tomé e Príncipe e costa da África, com objetivo de procurar cores "sólidas", principalmente a vermelha, muito apreciada na época, que pudessem ser aplicadas com diferentes mordentes em diversos objetos. Ao tratar deste assunto, Francisco Vieira Goulart incluiu alguns comentários sobre a possibilidade de aclimatar a Ruiva (Rubia tinctorium), discorrendo também sobre a nociva prática das queimadas em nosso sistema de agricultura, bem como sobre o extrativismo descontrolado da Tajubá ou Tatajiba (Chlorophora tinctoria (L.) Gaudich).

Outra operação foi a tentativa de preparar artificialmente uma água sulfurosa que imitasse a de Caldas da Rainha (Portugal), famosa pelos seus poderes curativos. Goulart preparou algumas amostras tendo como base uma "análise das águas realizada em 1795 por William Withering".

O $5^{\circ}$ Capítulo trata da análise das águas da "Quinta das Laranjeiras", famosa na cidade do Rio de Janeiro por ser férrea. O Conde das Galveas ordenou o exame da referida água em outubro de 1812. Neste ponto, o relatório é mais detalhado em termos das operações químicas. Goulart descreve a preparação de amostras a partir de "protóxide de ferro e água destilada" e descreve a apresentação que fez ao Rei:

“(...) na sua Augusta Presença fez aparecer o ferro dissolvido por meio de prussiate de cal e adição de algum ácido, mostrando a linda cor safira que é própria do hydro-prussiate-deferro"

As amostras, coletadas em 18 de junho de 1813 foram levadas ao Laboratório Químico-Prático para que fossem realizados exames comparativos detalhados neste documento, sendo comprovada a presença de proth'oxide de ferro ( $\mathrm{sic}$ ), sílica e alumina. O relatório com as observações realizadas foi entregue ao Conde das Galveas.

Ainda neste capítulo, Goulart comenta o aparecimento de um folheto datado de 1819 e intitulado "Instruções para os viajantes empregados na Colônia", que inclui uma análise realizada em 1811, da mesma fonte, feita por José Caetano de Barros que, como já foi dito, trabalhava no Laboratório do Conde da Barca, e que registra a ausência de ferro. Goulart se declara indignado com a divulgação desses resultados, já que suas análises foram feitas posteriormente (1813) e colocavam em dúvida o que chamou de "pseudo-análise", feita, segundo ele, apenas com o intuito de desacreditar as virtudes daquela água e "ficar em voga a que ele (Barros) preparava no Laboratório do Conde da Barca". Goulart critica também o trabalho "Argilas do Brasil", publicado no folheto supra citado, no qual o autor afirma ter examinado mais de 200 diferentes argilas, sem conseguir produzir o vidrado da porcelana. Para Goulart a divulgação deste trabalho desanimaria qualquer pessoa que quisesse fabricar louça no Brasil $^{26}$. Ele aproveita para alertar sobre a necessidade de se fazer e divulgar um "inventário científico do que possuímos" e também de se instalar uma Escola onde se "ensine a química aplicada às Artes", sujeita à Junta do Comércio, vista, portanto, como uma corporação permanente que evitaria que ocorresse o que aconteceu com o Laboratório Químico-Prático.

A descrição mais extensa do manuscrito é a que refere às experiências com vinhos e aguardentes, sendo curiosa a motivação para sua realização. Goulart nos relata que, tendo o Conde das Galveas visitado Antônio de Araújo Azevedo, futuro Conde da Barca, este lhe mostrou que a venda da aguardente e dos licores era a principal receita do laboratório. Galveas então ordenou que Goulart fosse ao referido laboratório e observasse a maneira pela qual era preparada a aguardente. Assim fez o Diretor, sendo recebido por José Caetano de Barros que lhe explicou o processo, acreditando tratar de pessoa que não sabia química e, por último mostrou o alambique em que se fazia a operação. Goulart demonstrou ter conhecimento do artigo publicado no periódico $O$ Patriota, a respeito do alambique escocês existente no laboratório do Conde da Barca ${ }^{27}$.

Após relatar sua visita e demonstrar seus conhecimentos das experiências realizadas anteriormente em Portugal, entre 1804 e 1807, foram iniciadas as operações com bebidas fermentadas. Goulart relata ter lido as memórias escritas sobre o assunto na coleção da Academia Real das Ciências de Lisboa e no Jornal de Coimbra, dizendo ser

"o primeiro químico nacional a comparar a gravidade específica do mosto com o produto alcoólico da fermentação".

Descreve ainda longamente, o processo de fermentação, principalmente quanto à adição de água e açúcar para acelerar o processo, partindo em seguida para a fabricação de vinhos a partir de laranja, banana, abacaxi, cana de açúcar e melado (rapadura), sendo que da cana as experiências realizadas foram no sentido de fabricar "vinho, vinagre e aguardente". As experiências iniciaram-se em agosto de 1812 e terminaram em 1819.

Estas foram as atividades realizadas no Laboratório QuímicoPrático por Francisco Vieira Goulart no período de seu funcionamento entre 1812 e 1820.

\section{O FIM DO LABORATÓRIO QUÍMICO-PRÁTICO}

No Capítulo 8 do documento "Ensaio Histórico Analítico das Operações do Laboratório Químico-Prático do Rio de Janeiro”, Francisco Vieira Goulart relata como se deu o término das atividades do laboratório. 
Como já relatamos, no período em que o Ministério de Estado e Negócios da Marinha e Domínios Ultramarinos esteve a cargo do Conde da Barca, o Laboratório Químico-Prático inicia sua decadência, período este marcado pela discussão sobre a necessidade de transferência do estabelecimento.

Quando o Conde dos Arcos toma posse em fevereiro de 1818, Goulart apressa-se em lhe apresentar uma "Memória sobre as vistas com que fora criado o laboratório, e as operações que nele se fizeram até aquela época", o que parece-nos ser um esboço do documento aqui analisado, mas ouviu do Conde que o Laboratório QuímicoPrático não era no momento a prioridade de sua repartição.

O próprio Goulart encontra um novo local para a instalação do Laboratório, no mesmo bairro de Mata-Porcos, porém o Rei manda comprar algumas casas para o estabelecimento do Museu Real e, ao receber o ofício com a solicitação em dezembro de 1818, o Ministro responde não ter dinheiro a sua disposição e que não iria solicitá-lo ao Rei, ficando claro, neste momento, a intenção de acabar com o estabelecimento.

Apesar do Laboratório ter sido extinto em 22 de dezembro de 1819, seu Diretor, Francisco Vieira Goulart, só recebeu um aviso com data de 12 de janeiro de 1820, participando a suspensão do Laboratório, com instruções para enviar ao Arsenal Real a relação dos objetos pertencentes ao mesmo, de modo que a casa fosse evacuada até o fim do mês, acrescentando, ainda, que a pensão a que tinha direito, referente à metade de seu ordenado, seria paga pela junta da Fazenda de Angra (Portugal), para cuja Catedral deveria se recolher, em virtude de sua condição de cônego.

Solicitando dois anos de licença para continuar residindo no Brasil, até a data em que escreveu este documento, que acreditamos ter sido ainda no ano de 1820, Goulart não havia recebido a tal pensão e prometia denunciar em obra separada o "escandaloso motivo deste iníquo procedimento".

\section{CONCLUSÕES}

A chegada de D. João VI provocou o surgimento das primeiras instituições científicas no Rio de Janeiro e a conseqüente transferência de material e de pessoal ligado à ciência. Ferraz ${ }^{6}$ utiliza os termos "introdução", "transmissão" e "difusão" da ciência para abordar o período posterior a 1808, uma vez que "muda o cenário, mas as pessoas são as mesmas, ainda que as dificuldades ganhem outra forma".

O Laboratório Químico-Prático será a primeira iniciativa estatal de uma Química prática, fora do âmbito do ensino nos cursos de engenharia e de medicina, em que tinha um caráter de ciência básica, necessária a outros conhecimentos. Nova iniciativa de criação de um estabelecimento para análise de nossas matérias primas vegetais e minerais somente virá à tona em 1824, quando da criação do laboratório químico do Museu Nacional.

Apesar de não termos encontrado outras provas das atividades realizadas no Laboratório Químico-Prático do Rio de Janeiro, podemos tirar algumas conclusões a partir do documento encontrado. Como dissemos inicialmente, o mesmo parece ter sido escrito por volta de 1820, após o término das atividades do Laboratório por Francisco Vieira Goulart, o que nos permite retificar as informações de que José Maria Bontempo, professor de matéria médica da Escola Anatômica, Cirúrgica e Médica da Corte, ou mesmo José Caetano de Barros $^{17}$, tenham sido diretores do estabelecimento.

O nome do estabelecimento está plenamente em concordância com as operações realizadas e também com sua vinculação ao Ministério dos Domínios Ultramarinos, uma vez que realizava análises de materiais oriundos das diversas colônias portuguesas com vistas a incentivar o comércio entre elas, e também com a China.

Pouco conseguimos levantar sobre as atividades científicas de
Francisco Vieira Goulart. Os documentos sobre ele são poucos e esparsos e, na área de química, nada conseguimos localizar. A leitura do documento dá a entender que ele estava apto a realizar as operações do Laboratório.

A decadência do Laboratório Químico-Prático, como descrito no documento, inicia-se na gestão do conde da Barca à frente do Ministério Ultramarino e, segundo o autor, deve-se ao fato de o Conde ter um laboratório na Corte onde operações idênticas eram realizadas. A estatização do laboratório do Conde da Barca, logo após seu falecimento e dois meses antes da extinção do Laboratório Químico-Prático, corrobora as queixas de Vieira Goulart, embora ele não mencione este fato no documento.

Não há menção a trabalhos de análises de drogas farmacêuticas ou mesmo que o Laboratório tenha funcionado como dispensatório para fornecimento de medicamentos, sendo assim não podemos relacionar o término de suas atividades a este fato, ao contrário do que afirmam vários autores citados no início deste artigo ${ }^{1,3,4}$.

\section{AGRADECIMENTOS}

A autora agradece às seguintes pessoas e instituições:

D. Pedro Carlos de Orleans e Bragança, por facultar-lhe o acesso aos documentos do Arquivo Grão-Pará;

Arquivo do Museu Imperial, Petrópolis, Rio de Janeiro.

\section{REFERÊNCIAS E NOTAS}

1. Rheinboldt, H. Em As ciências no Brasil; Azevedo, F.;(org.); Ed. Melhoramentos: Rio de Janeiro, 1955, vol. 2, p. 21-24.

2. Mathias, S. Em História das ciências no Brasil; Ferry, M. G.; Motoyama, S., coord.; EPU/Edusp: São Paulo, 1979, p. 98.

3. Schwartzman, S.; Formação da comunidade científica no Brasil, Ed. Nacional: São Paulo; FINEP: Rio de Janeiro, 1979, p. 62-63.

4. Gonçalves, A. L.; Difusão da Química no Brasil (1808-1908), Ed. Sobreondas: Rio de Janeiro, 1993.

5. Carrara Jr. E.; Meirelles, H.; A Indústria Química e o desenvolvimento do Brasil, Metalivros: São Paulo, 1996.

6. Ferraz, M. H. M.; As ciências em Portugal e no Brasil (1772-1822): o texto conflituoso da química, EDUC: São Paulo, 1997.

7. Mello Oliveira, F. M. de; Revista Pharmaceutica 1884, I, 131.

8. Do artigo original de Melo Oliveira, localizamos apenas três páginas referentes à Introdução do documento, conforme a ref. 7. Até a presente data só foi localizado este número da Revista Pharmaceutica, que faz parte do acervo da Biblioteca da Escola de Farmácia e Bioquímica da Universidade Federal de Ouro Preto.

9. Costa, O. A.; Revista da Sociedade Brasileira de Química 1948, XVII, 95.

10. Oswaldo Costa em seu artigo faz referência a três partes do artigo de Melo Oliveira que haviam sido publicadas ainda no tomo I (1884) da Revista Pharmaceutica.

11. Cunha, S. E.; Revista de Farmácia e Odontologia 1952, 131.

12. Oliveira, J. C. de; Tese de Doutorado, Universidade Federal do Rio de Janeiro, Brasil, 1998

13. Silva, M. B. N. da; O império luso-brasileiro, 1750-1822, Editorial Estampa Ltda.: Lisboa, 1986.

14. Lima, O.; D. João VI no Brasil, Topbooks: Rio de Janeiro, 1996.

15. Coleção de Leis do Brasil, Tipografia Nacional: Rio de Janeiro, 1889.

16. Arquivo Público do Estado de São Paulo, Documentos interessantes para a história e costume de São Paulo, vol. 89, p. 17-19.

17. Azevedo, M. de; O Rio de Janeiro, B. L. Garnier: Rio de Janeiro, 1877.

18. Goulart, F. V.; Memória sobre os defeitos que se encontram no systema metrologico, que se organizou para o Brasil pela Commissão nomeada pelo Decreto de 8 de janeiro de 1833, Tipografia Nacional: Rio de Janeiro, 1836.

19. Segundo Goulart, o comprimento da vara portuguesa era a mesma da vara brasileira (40 polegadas ou 11 decímetros) e que a comissão encarregada de estruturar o sistema métrico brasileiro ao adotar o princípio da diferença entre as varas, utilizava-se de um critério eminentemente político, que desejava estabelecer mais um ponto de separação entre as duas nações. O sistema métrico francês, utilizado até hoje no país, foi estabelecido em 1862.

20. Gerson, B.; História das ruas do Rio, $5^{\mathrm{a}}$ ed., Lacerda Ed.: Rio de Janeiro, 2000 . 
21. Marrocos, L. J. dos S.; Memórias e Cotidiano do Rio de Janeiro no tempo do rei, Ministério da Cultura, Fundação Biblioteca Nacional: Rio de Janeiro, http:// www.bn.br, acessada em Janeiro 2002

22. AHCML, maço 718, relação de materiais enviada por Goulart, Rio de Janeiro, 23 de fevereiro de 1812; ofício do Conde do Redondo ao diretor do Laboratório Químico da Casa da Moeda de Lisboa, Gregório José Seixas, Lisboa, 6 de junho de 1812.

23. AHCML, maço 718, minuta de 16 de junho de 1812 .

24. AHCML, cópia da relação e da carta de Goulart, datada de 18 de setembro de 1812 .

25. Ao se fazer cortes na cápsula da papoula, ainda verde, obtém-se um suco leitoso, o ópio (a palavra ópio, em grego, quer dizer suco). Quando seco, este suco passa a se chamar pó de ópio. Nele existem várias substâncias com grande atividade biológica. A mais conhecida é a morfina, $\left(\mathrm{C}_{17} \mathrm{H}_{19} \mathrm{O}_{3} \mathrm{~N}\right)$ palavra que vem do deus da mitologia grega Morfeu, o deus dos sonhos.
26. Seus comentários mostram seu conhecimento do processo de fabricação de porcelanas, principalmente no que se refere ao caulim $\left(\mathrm{Al}_{4}\left(\mathrm{SiO}_{4} \mathrm{O}_{10}\right)(\mathrm{OH})_{8}\right)$, conhecido no Brasil pelo nome indígena de tabatinga (barro branco).

27. Marques, G.; O Patriota, 1813, 2 ( $1^{a}$ subscrição), 99-105, "Memória sobre um alambique existente no laboratório do Excelentíssimo Sr. Antônio de Araujo Azevedo, que contém as invenções mais modernas praticadas na Escócia, e a qual se fizeram algumas adições a sua, perfeição." 